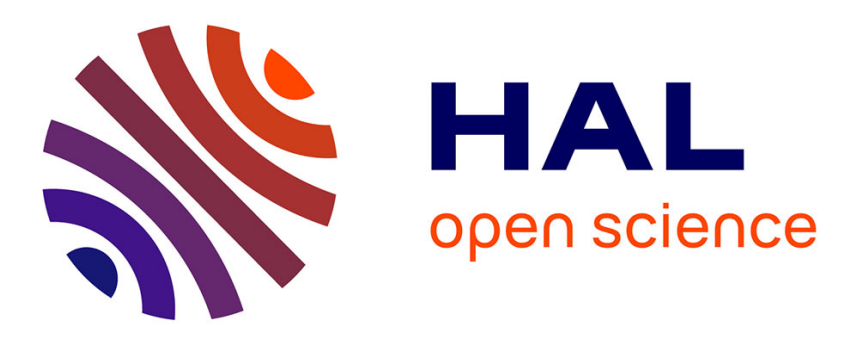

\title{
Hydraulic Modeling of a Mixed Water Level Control Hydromechanical Gate
}

\author{
Ludovic Cassan, Jean-Pierre Baume, Gilles Belaud, Xavier Litrico, \\ Pierre-Olivier Malaterre, José Ribot-Bruno
}

\section{- To cite this version:}

Ludovic Cassan, Jean-Pierre Baume, Gilles Belaud, Xavier Litrico, Pierre-Olivier Malaterre, et al.. Hydraulic Modeling of a Mixed Water Level Control Hydromechanical Gate. Journal of Irrigation and Drainage Engineering, 2011, vol. 137, pp. 446-453. 10.1061/(ASCE)IR.1943-4774.0000305 . hal-00842380

\section{HAL Id: hal-00842380 \\ https://hal.science/hal-00842380}

Submitted on 8 Jul 2013

HAL is a multi-disciplinary open access archive for the deposit and dissemination of scientific research documents, whether they are published or not. The documents may come from teaching and research institutions in France or abroad, or from public or private research centers.
L'archive ouverte pluridisciplinaire HAL, est destinée au dépôt et à la diffusion de documents scientifiques de niveau recherche, publiés ou non, émanant des établissements d'enseignement et de recherche français ou étrangers, des laboratoires publics ou privés. 


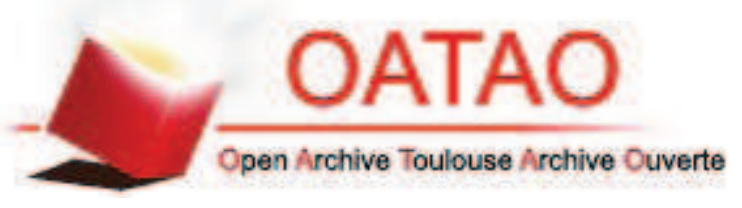

OATAO is an open access repository that collects the work of Toulouse researchers and makes it freely available over the web where possible.

This is an author-deposited version published in : http://oatao.univ-toulouse.fr/ Eprints ID : 9011

To link to this article : DOI: 10. 1061/(ASCE)IR.1943-4774.0000305

URL : http://dx.doi.org/10.1061/(ASCE)IR.1943-4774.0000305

Open Archive TOULOUSE Archive Ouverte (OATAO)

To cite this version : Cassan, Ludovic and Baume, Jean-Pierre and Belaud, Gilles and Litrico, Xavier and Malaterre, Pierre-Olivier and Ribot-Bruno, José Hydraulic Modeling of a Mixed Water Level Control Hydromechanical Gate. (2011) Journal of Irrigation and Drainage Engineering, vol. 137 ( $\left.{ }^{\circ} 7\right)$. pp. 446-453.

Any correspondence concerning this service should be sent to the repository administrator: staff-oatao@listes.diff.inp-toulouse.fr 


\title{
Hydraulic Modeling of a Mixed Water Level Control Hydromechanical Gate
}

\author{
Ludovic Cassan'; Jean-Pierre Baume²; Gilles Belaud³; Xavier Litrico4; \\ Pierre-Olivier Malaterre; ${ }^{5}$ and José Ribot-Bruno ${ }^{6}$
}

\begin{abstract}
This article describes the hydraulic behavior of a mixed water level control hydromechanical gate present in several irrigation canals. The automatic gate is termed "mixed" because it can hold either the upstream water level or the downstream water level constant according to the flow conditions. Such a complex behavior is obtained through a series of side tanks linked by orifices and weirs. No energy supply is needed in this regulation process. The mixed flow gate is analyzed and a mathematical model for its function is proposed, assuming the system is at equilibrium. The goal of the modeling was to better understand the mixed gate function and to help adjust their characteristics in the field or in a design process. The proposed model is analyzed and evaluated using real data collected on a canal in the south of France. The results show the ability of the model to reproduce the function of this complex hydromechanical system. The mathematical model is also implemented in software dedicated to hydraulic modeling of irrigation canals, which can be used to design and evaluate management strategies.
\end{abstract}

Author keywords: Numerical models; Hydraulic structures; Gates; Water levels; Field tests.

\section{Introduction}

In the past, irrigation canals have been operated with nonadjustable devices (spillways, proportional diversions, and others) or manually operated adjustable structures (gates). Automatic hydromechanical gates were developed in the twentieth century to better control water levels and water distribution. To our knowledge, the first commercial automatic gates were the AMIL gates. These gates are hydromechanical gates that use a float and two counterweights to maintain the water level upstream from the gate close to a setpoint. These gates were designed in the 1930s by the French company Neyrpic (later called Neyrtec, then Alsthom Fluide, it now belongs to the Gec-Alstom Group). Other hydromechanical gates have been designed by using alternative approaches and technologies for an upstream water level control.

${ }^{1}$ Researcher, UMR G-EAU, Cemagref, 361 rue J-F Breton, 34196 Montpellier Cedex 5, France (corresponding author). E-mail: ludovic .cassan@cemagref.fr

${ }^{2}$ Research Engineer, UMR G-EAU, Cemagref, 361 rue J-F Breton, 34196 Montpellier Cedex 5, France. E-mail: jean-pierre.baume@ cemagref.fr

${ }^{3}$ Assistant Professor, UMR G-EAU, SupAgro/IRD, 361 rue J-F Breton, 34196 Montpellier Cedex 5, France. E-mail: gilles.belaud@ supagro.inra.fr

${ }^{4}$ Researcher, UMR G-EAU, Cemagref, 361 rue J-F Breton, 34196 Montpellier Cedex 5, France. E-mail: xavier.litrico@cemagref.fr

${ }^{5}$ Researcher, UMR G-EAU, Cemagref, 361 rue J-F Breton, 34196 Montpellier Cedex 5, France. E-mail: pierre-olivier.malaterre@cemagref .fr

${ }^{6}$ Research Engineer, UMR G-EAU, Cemagref, 361 rue J-F Breton, 34196 Montpellier Cedex 5, France. E-mail: jose.ribot-bruno@cemagref .fr
The Begemann and Vlugter gates are examples of theses structures and were designed by Dutch engineers (Vlugter 1940; Brouwer 1987; Burt et al. 2001; Litrico et al. 2005; Belaud et al. 2008). Upstream water level control is effective when water is distributed to users by using a fixed rotation schedule. This control strategy is easy to implement and favored by canal managers but rigid for the water users. It is the source of possible important water losses.

The Neyrpic company later developed hydromechanical gates for downstream water level control. The AVIS and AVIO gates have the important advantage of being adapted for a type of canal regulation called downstream control (Malaterre et al. 1998). This type of control allows on-demand water distribution to water users, as opposed to a fixed-rotation schedule. To our knowledge, the AVIS and AVIO gates are the only hydromechanical gates designed for downstream control of irrigation canals. In some cases, the upper reaches of large irrigation canals are managed by an upstream control strategy, and the lower reaches are managed by a downstream control strategy. This prevents frequent head discharge changes in the upstream part and adapts the release to the water demand in the downstream reaches. These two approaches can be used in combination only if storage volume is available in the reaches and properly managed. The use of this water storage can be managed by a third type of gate called mixed gates, also developed by Neyrpic. These gates are the only example of such advanced automatically operated gates using only hydromechanical principals.

Hydromechanical gates are unique because they do not require power or electronic components. They only need regular maintenance (painting and greasing). They are very well suited for difficult environments, such as those prevailing in developing countries or in remote locations. Their properties are all the more interesting in the context of increasing energy costs and possible power outages. Because of their performance and robustness properties, they are still installed on new irrigation canals (e.g., the PHLC canal in Pakistan and the Atbarra canal in Sudan) even though electronically controlled and motorized gates are increasing their market shares. 
The AVIS, AVIO, and mixed gates have been built in several countries, such as France, Algeria, Morocco, Spain, Portugal, Brazil, and the United States (Cemagref 2004) and have been installed on hundreds of irrigation canals.

Several examples of irrigation canals using mixed gates exist, such as the Beni Moussa canal of the Tadla irrigation scheme canal in Morocco, where the original gates installed in the 1950s are still very well maintained. Although mixed gates have been used for decades, only a few studies mathematically modeled their hydraulic behavior (Ramirez Luna 1997). Their hydraulic behavior is complex because it is based on a series of tanks connected by multiple orifices and weirs. The tanks and connections are designed in such a way that the mixed gate can simultaneously maintain a downstream water level and store water in the upstream reach. The mixed gate can be used without human intervention because two security modes prevent overflow and dewatering of reaches. Mathematical models of these gates are useful to design and analyze hydraulic management strategies in irrigation canals equipped with them. They are also useful to help adjust their characteristics in the field or in a design process.

The purpose of this paper is to develop a mathematical model of the mixed gate that can be implemented in a software solving openchannel flow equations. The paper is organized as follows. First, the first section provides a physical description of the gate and define its general functioning. The next section develops a mathematical model of the gate, taking into account the various hydraulic devices. Subsequently, the model is used to study its sensitivity to various parameters. Finally, the model results are compared to experimental measurements from an operating mixed gate installed in a real channel network.

\section{Gate Design and Behavior}

The mixed gate is designed to manage the difference between a supply discharge $Q_{p}$ provided into the network by pumping or derivation and a demanded discharge $Q_{d}$ corresponding to water offtakes. If $Q_{p}>Q_{d}$, the upstream reach will be used for water storage, and the upstream water level will increase. If this difference persists, or during transient if $Q_{p}$ increases rapidly, the gate will open at the maximum opening to avoid overtopping in the upstream reach. If $Q_{p} \leq Q_{d}$, then the mixed gate allows the system to fulfill the demand as long as the discharge through the gate is equal to $Q_{d}$ and until the upstream level reaches a minimum value. The gate closes completely when the discharge variation persists or

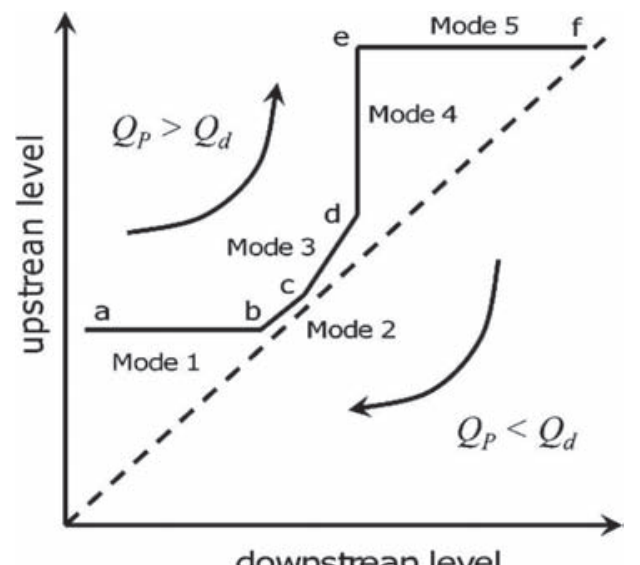

downstrean level

Fig. 1. Design curve of the upstream level as a function of the downstream level during transient, if $Q_{d}$ decreases rapidly. Demands can no longer be fulfilled, but the upstream water level is maintained at its setpoint.

The overall functioning of the mixed gate can be described by the design relation between the upstream level $Z_{u}$ and the downstream level $Z_{d}$, as depicted in Fig. 1 (Alsthom 1993). This curve shows that the mixed gate is similar to a constant downstream level gate (AVIS) with two security modes. These models for low and high values of downstream level prevent the complete emptying and overflowing of the upstream reach, respectively. These modes are called Mode 1 and Mode 5, respectively (see Fig. 1).

\section{Physical Description of the Mixed Gate}

A mixed gate consists of two main parts: a set of side tanks and a metal frame with floats and a gate leaf (Figs. 2 and 3). The first part is a set of side tanks connected by weirs and orifices. Figs. 3 and 4 show the geometry of the tanks and their connections.

The inlet tank is connected to the upstream reach of the channel through a circular orifice $\mathrm{O}_{1}$. Water can flow into the upstream regulation tank through submerged orifice $\mathrm{O}_{3}$ or above the weir $W_{10}$ (if the flow depth is sufficient). Water is evacuated from the upstream regulation tank by three different orifices, depending on the water depth.

- The orifice $\mathrm{O}_{4}$ is always submerged; it connects the upstream tank to the downstream tank. Water flows out of $\mathrm{O}_{4}$ when the

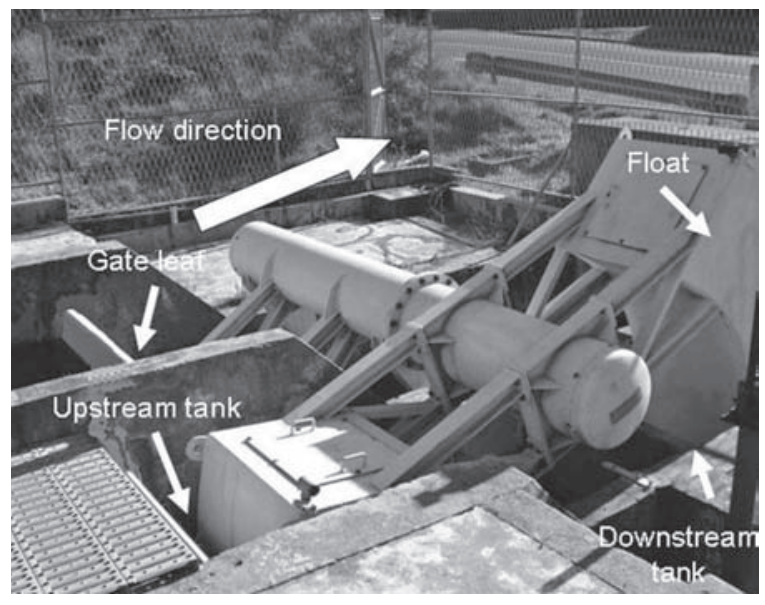

Fig. 2. Mixed gate located on the Bas-Rhône Languedoc canal

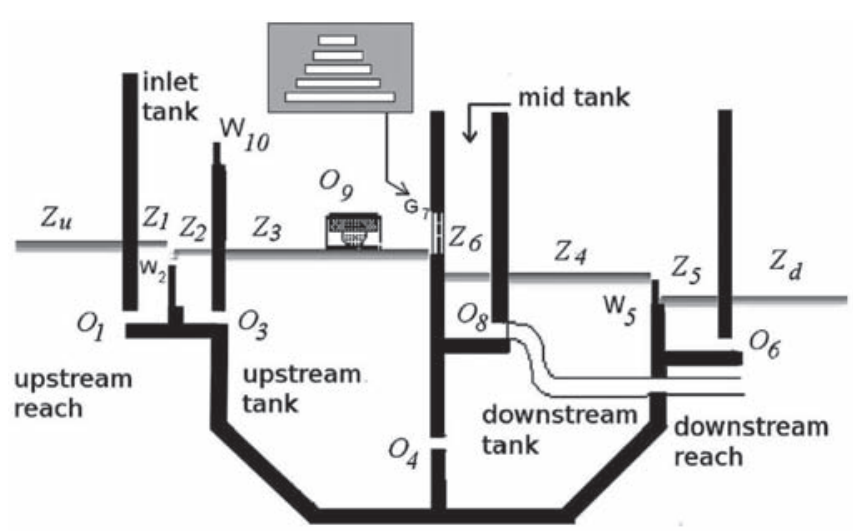

Fig. 3. Hydraulic structures, position of side tanks and front view of the grid; floats are installed in the upstream tank and in the downstream tank (not shown) 


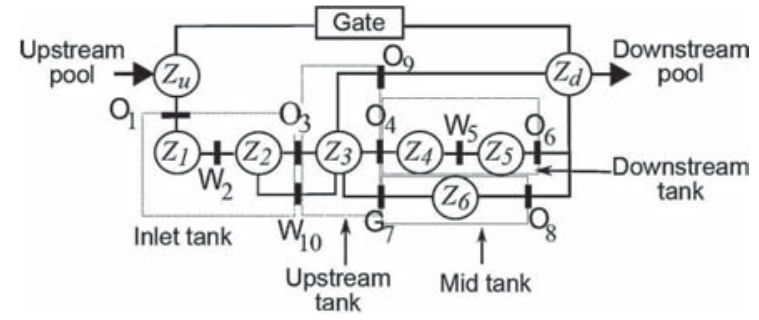

Fig. 4. Flowchart of the mixed gate

upstream water level is higher than both $Z_{2}$ and the downstream water level $Z_{d}$.

- The grid $\mathrm{G}_{7}$ is shaped so that the width of opening decreases as the water level rises (Fig. 3). Water going through $\mathrm{G}_{7}$ enters the middle tanks.

- The orifice $\mathrm{O}_{9}$ flows directly into the downstream reach.

The downstream tank has a weir $\mathrm{W}_{5}$ that maintains a minimum water level. It is connected to the downstream reach through the

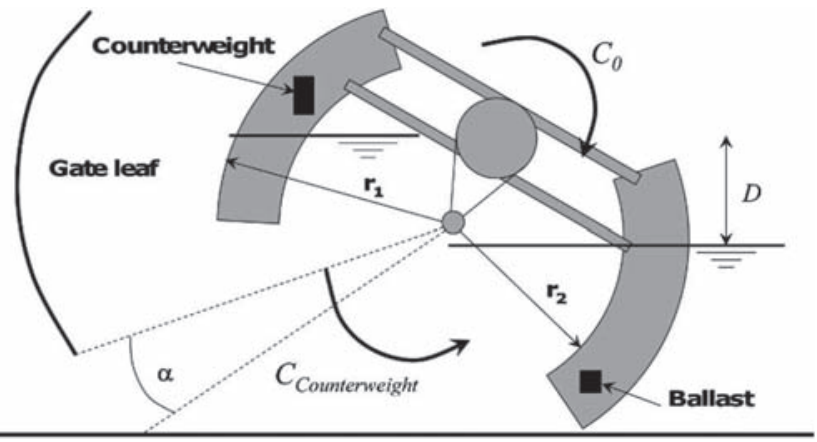

Fig. 5. Description of torques acting on gate and the counterweight system orifice $\mathrm{O}_{6}$. Similarly, a middle tank is linked with the downstream reach through the orifice $\mathrm{O}_{8}$.

The second part is composed of a sector float and a gate leaf, both of which are mounted on a metal frame (Fig. 2). This part can revolve around a rotational axis. The gate leaf has a trapezoidal section, and it is placed across the channel to regulate the flow in the canal at the gate location. The floats are weighted so that the gate leaf and the floats are in equilibrium for the whole range of possible openings. Therefore, without water in the tanks, the torque on the axis of rotation because of the weight of the gate leaf is exactly compensated by the torque caused by the ballast (Fig. 5). Therefore, the opening or closing of the gate will be only attributable to the difference in water levels between the upstream $\left(Z_{3}\right)$ and downstream tanks $\left(Z_{4}\right)$, respectively.

The orifices $\mathrm{O}_{3}, \mathrm{O}_{4}, \mathrm{O}_{6}$, and $\mathrm{O}_{9}$ are equipped with shutters designed to block off part of the orifices. They allow manual adjustment to the orifice openings and modification of the shape of the design curve, as shown subsequently.

\section{Operation Modes}

Water can flow through different combinations of orifices and weirs depending on the upstream and downstream water levels. These different flow patterns determine the operational modes of the gate [Figs. 6(a)-6(e)].

Five different modes can be distinguished in the relationship between upstream and downstream levels, as depicted in Fig. 1. These five modes can be linked to the flow patterns between the tanks (Fig. 6).

Mode 1 [Fig. 6(a)] regulates the upstream water level $Z_{u}$ and is represented by the line a-b in Fig. 1. This mode occurs when the weir $\mathrm{W}_{5}$ is under free flow conditions. In that case, there is no influence of the downstream water level $Z_{d}$ on the water levels in the upstream and downstream tanks, and the gate behaves similarly to an AMIL gate.

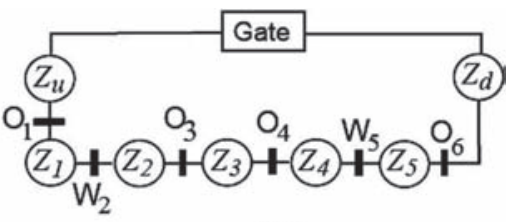

(b)

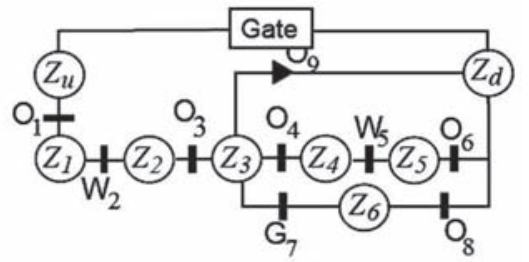

(d)

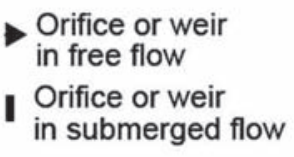

Orifice or weir

Orifice or weir

in submerged flow

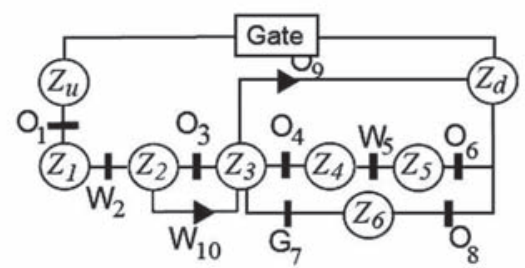

(e)

Fig. 6. Flowchart for the five modes 
In Mode 2 [Fig. 6(b), line b-c in Fig. 1], the floats impose a constant head difference between the upstream and downstream tanks, $D=Z_{3}-Z_{4}$. Because the orifice $O_{4}$ is submerged, its discharge $Q_{4}$ is also constant. Because $\mathrm{O}_{1}, \mathrm{~W}_{2}, \mathrm{O}_{3}, \mathrm{O}_{4}, \mathrm{~W}_{5}$, and $\mathrm{O}_{6}$ are submerged, the head losses $Z_{u}-Z_{1}, Z_{2}-Z_{3}$, and $Z_{5}-Z_{d}$ are also constant. Moreover, $Z_{1} \approx Z_{2}$, and $Z_{4} \approx Z_{5}$. Consequently, the difference between the upstream and downstream levels is also constant. This mode occurs when $Z_{3}$ is below the level of the grid bottom $\left(\mathrm{G}_{7}\right)$.

Mode 3 [Fig. 6(c), line c-d in Fig. 1], imposes a linear relationship between $Z_{u}$ and $Z_{d}$. Similar to the previous mode, the discharge in the downstream tank $Q_{4}$ remains constant, but $Z_{2}-Z_{3}$ depends on the flow through the grid $G_{7}$. The shape of $\mathrm{G}_{7}$ ensures that $Z_{2}$ increases linearly with $Z_{3}$.

Mode 4 [Fig. 6(d), line d-e in Fig. 1], begins when water flows through orifice $\mathrm{O}_{9}$. It provides a constant downstream level regulation. An increase in $Z_{u}$ causes a limited increase of $Z_{3}$ because of $\mathrm{O}_{9}$ and $\mathrm{G}_{7}$ and then a limited variation of $Z_{d}$. The flow through $\mathrm{O}_{9}$ may be manually adjusted by using a shutter that controls the variation of $Z_{d}$ with $Z_{u}$.

Mode 5 [Fig. 6(d), line e-f in Fig. 1] occurs when water flows over the weir $\mathrm{W}_{10}$. The principle is identical to Mode 4 , but here $Z_{u}$ is maintained nearly constant by the weir $\mathrm{W}_{10}$.

\section{Gate Equilibrium Design}

The torque because of floats on the axis of the gate, $C_{0}$, is a function of the difference $D$ between water levels in the upstream and downstream tanks. This torque is calculated as follows (Alsthom 1993):

$$
C_{0}=\frac{\rho g L_{f} D\left(r_{1}^{2}-r_{2}^{2}\right)}{2 g}
$$

where $L_{f}(\mathrm{~m})=$ width of floats; $r_{1}$ and $r_{2}(\mathrm{~m})=$ outer and inner radius of the floats, respectively; $\rho\left(\mathrm{kg} / \mathrm{m}^{3}\right)=$ water density; and $g\left(\mathrm{~m} / \mathrm{s}^{2}\right)=$ gravitational acceleration.

The gate is in equilibrium for any openings (with water in the tanks); a counterweight is placed in the upstream float, which produces an opposite torque, exactly compensating $C_{0}$. This ensures that, for any value of the discharge, there is a constant difference $D$ between the upstream and the downstream levels in the tanks. Indeed, if the difference in the upstream and downstream level decreases, the counterweight will tend to close the gate. Conversely, if this difference increases, the counterweight will tend to open the gate. Flows in the side tanks will vary with changing water levels to establish a new equilibrium state. This state only depends on the water levels in the upstream and downstream reaches, so the relationship between water levels in the upstream and downstream tanks is independent of the discharge in the main channel.

\section{Modeling of the Mixed Gate}

The proposed mathematical model assumes the gate is in equilibrium for any given upstream $Z_{u}$ and downstream $Z_{d}$ water levels. Because water levels in the tanks respond rapidly in comparison with changes in the water levels $Z_{u}$ and $Z_{d}$, transient dynamic effects of the gate can be neglected (Ramirez Luna 1997). A formal relationship between upstream and downstream levels can be derived depending on the different devices included in the mixed gate (weir and orifice elevation, orifice opening). Equations for the calculation of discharges and water depths were solved with Matlab software and are given below (Cemagref 2004; Sepulveda and Gomez 2009).

The hydraulic behavior of the gate has been modeled to replicate a curve $Z_{u}=f\left(Z_{d}\right)$ that reflects the actual water levels in the tanks. For a given hydraulic structure, $h_{1}=$ upstream head; $h_{2}=$ downstream head; $w=$ orifice opening; $L=$ equivalent width (Chow 1959); $C_{d}=$ discharge coefficient; $D_{0}=$ orifice diameter; and $Q=$ discharge.

For a free flow weir $\left(h_{2} \leq \frac{2}{3} h_{1}\right.$ and $\left.h_{1}<k D_{0}\right)$

$$
Q=C_{d} L \sqrt{2 g} h_{1}^{(3 / 2)}
$$

For a submerged weir $\left(h_{2}>\frac{2}{3} h_{1}\right.$ and $\left.h_{1} \leq k D_{0}\right)$

$$
Q=C_{d} \frac{3 \sqrt{3}}{2} L h_{2} \sqrt{2 g\left(h_{1}-h_{2}\right)}
$$

For a free flow orifice $\left(h_{2} \leq \frac{2}{3} h_{1}\right.$ and $\left.h_{1}>k D_{0}\right)$

$$
Q=C_{d} \frac{2}{3 \sqrt{3}} L \sqrt{2 g}\left[h_{1}^{(3 / 2)}-\left(h_{1}-k D_{0}\right)^{(3 / 2)}\right]
$$

For a partially submerged orifice $\left[h_{2} \leq \frac{2}{3} h_{1}+\left(k D_{0} / 3\right)\right.$ and $\left.h_{1}>k D_{0}\right]$

$$
Q=C_{d} L \sqrt{2 g}\left[h_{2} \sqrt{h_{1}-h_{2}}-\frac{2}{3 \sqrt{3}}\left(h_{1}-k D_{0}\right)^{(3 / 2)}\right]
$$

For a completely submerged circular orifice $\left[h_{2}>\frac{2}{3} h_{1}+\right.$ $\left(k D_{0} / 3\right)$ and $\left.h_{1}>k D_{0}\right]$

$$
\begin{gathered}
Q=C_{d} L k D_{0} \sqrt{2 g\left(h_{1}-h_{2}\right)} \\
k=\frac{w}{D_{0}}
\end{gathered}
$$

where $k \in\left[\begin{array}{ll}0 & 1\end{array}\right]=$ relative orifice opening.

All orifices function as weirs at low upstream water levels. To ensure flow continuity through the orifice and to take into account the contraction for orifice flow $\left[C_{d}=0.60\right.$, as recommended in Bos (1989)], a continuous increase of $C_{d}$ with the dimensionless depth $\left(h_{1} / w\right)$ is proposed as follows:

$$
C_{d}=\frac{\left(C_{d 0}+C_{d W}\right)}{2}+\frac{\left(C_{d 0}-C_{d W}\right)}{\pi} \arctan \left(\beta \frac{h_{1}-w}{w}\right)
$$

where $C_{d O}=0.60$ and $C_{d W}=0.40$. Parameter $\beta$ defines the transition steepness between weir and orifice flow. A value $\beta=10$ gives a correct description of this transition, with a monotonic increase of $Q$ with $h_{1}$. Eq. (8) is not established by physical considerations, but it allows us to obtain a continuous expression. An additional equation results from the assumption of a constant difference in water levels between the upstream and downstream tanks (see Fig. 1):

$$
Z_{3}-Z_{4}=D
$$

Eq. (9) results from the correct balancing of the gate, as explained previously. The calculation proceeds sequentially from the downstream condition.

- The first step is to calculate the levels $Z_{5}, Z_{4}$, and $Z_{3}$ by using the fact that the same discharge $\left(Q_{4}\right)$ flows through $\mathrm{O}_{4}, \mathrm{~W}_{5}$, and $\mathrm{O}_{6}$. The nonlinear system of three discharge equations, Eq. (9), and four unknowns is solved by using a bisection method.

- The second step is the calculation of the flow through grid $\mathrm{G}_{7}$. The two discharge equations in $\mathrm{G}_{7}$ and $\mathrm{O}_{8}$ give $Z_{6}$ and the flow into the midtank $\left(Q_{7}\right)$.

- In the third step, the flow $Q_{9}$ through orifice $\mathrm{O}_{9}$ is calculated from the level $Z_{3}$ and the downstream level $Z_{d}$. 
- Finally, the water depths $Z_{2}, Z_{1}$, and $Z_{u}$ are determined from the discharge equations through hydraulic structures $\mathrm{W}_{2}, \mathrm{~W}_{10}, \mathrm{O}_{1}$, and $\mathrm{O}_{3}$ and the discharge balance in the upstream tank [Eq. (10)]:

$$
Q_{3}+Q_{10}=Q_{4}+Q_{9}+Q_{7}
$$

The grid $\mathrm{G}_{7}$ consists of several horizontal openings, the widths of which decrease with elevation. Therefore, $Q_{7}$ varies as a function of $Z_{3}$. To simplify, the computed equivalent width is established, denoted $L_{7}$. This equivalent width of grid $\mathrm{G}_{7}$ is calculated from the wetted area, which depends on the difference between $Z_{3}$ and $Z_{7}$. Given $Z_{3}, Z_{7}$ and $L_{7}$, the flow through the grid is described by Eqs. (2)-(6), according to the flow conditions.

\section{Sensitivity Analysis}

Before testing the model on experimental data, a sensitivity analysis was performed to ensure that our model can reproduce the design curve of a mixed gate. The design characteristics of the gate are presented in Table 1.

A simpler method to compute the design curve can be developed by considering the geometric characteristics of the gate. In this case it is assumed that $Z_{u}=Z_{1}, Z_{d}=Z_{4}$, and $Z_{d}$ is constant for Mode 4 . Then, the change of modes occurs when flow begins through or over the associated device (see "Operation Modes"). Compared with the curve based on the geometric characteristics, the curve based on the mathematical model is not strictly constant in Mode 4 (Fig. 7). The difference between the curves can be

Table 1. Design Characteristics of the Modeled Gate

\begin{tabular}{lccccc}
\hline Number & Type & Crest level $(\mathrm{m})$ & $C_{d W}$ & $C_{d 0}$ & $L$ or diameter $(\mathrm{m})$ \\
\hline 1 & Orifice & 0.7 & 0.4 & 0.6 & 0.2 \\
2 & Weir & 1.1 & 0.4 & - & 0.8 \\
3 & Orifice & 0.7 & 0.4 & 0.6 & 0.1 \\
4 & Orifice & 0 & 0.4 & 0.6 & 0.05 \\
5 & Weir & 0.9 & 0.4 & - & 1.2 \\
6 & Orifice & 0.5 & 0.4 & 0.6 & 0.1 \\
7 & Orifice & 1.4 & 0.4 & 0.6 & Computed \\
8 & Orifice & 0.6 & 0.4 & 0.6 & 0.1 \\
9 & Orifice & 1.6 & 0.4 & 0.6 & 0.15 \\
10 & Weir & 2.6 & 0.4 & - & 1.2 \\
\hline
\end{tabular}

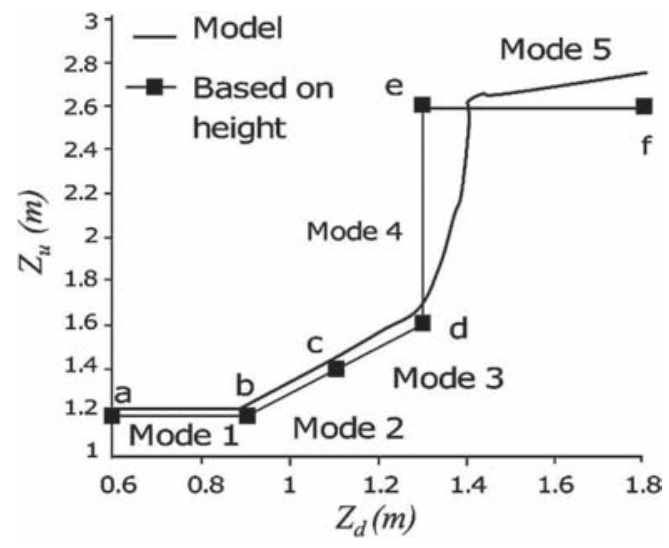

Fig. 7. Relationship between upstream and downstream water levels from model calculation and height of hydraulic devices; letter labels refer to Fig. 1 and mode analysis significant around the transition between Modes 3 and 4. At that point, the upstream level is estimated more accurately with the present mathematical model than with the curve based on the simpler method, described previously. In addition, the water level transitions do not exactly correspond to the heights of structures because they also depend on flows. Thus, the upstream water level is often higher than the corresponding height of the device.

A sensitivity analysis of the design curve was performed by varying the values of the orifice relative opening $k_{i}$, where $i$ corresponds to an orifice equipped with shutters. Fig. 8 shows the variation of the modeled curve when each orifice relative opening is changed. Modifying head losses between two tanks by closing the orifice allows $Z_{u}$ to either increase or decrease, depending on the orifice considered.

Openings $k_{4}$ and $k_{6}$ act on the difference $Z_{4}-Z_{d}$. This difference is generally limited because the discharge in the downstream tank is low and the head losses in $\mathrm{O}_{4}, \mathrm{~W}_{5}$, and $\mathrm{O}_{6}$ are small compared to those in the upstream part. This explains why both $k_{4}$ and $k_{6}$ have a limited influence on design curve.

The modification of $k_{3}\left(\mathrm{O}_{3}\right)$ influences the exchange between the upstream reach and the upstream tank. If $k_{3}$ is decreased, head losses through $\mathrm{O}_{1}, \mathrm{~W}_{2}$ and $\mathrm{O}_{3}$ increase, which indicates that $Z_{u}-Z_{3}$ increases. Because $Z_{3}$ and $Z_{4}$ are linked by Eq. (9), the difference between $Z_{u}$ and $Z_{d}$ increases.

Orifice $\mathrm{O}_{9}$ becomes effective when level $Z_{3}$ is high enough, therefore in Modes 4 and 5. Opening $\mathrm{O}_{9}$ causes the discharge in the upstream tank to increase, then the head loss in $\mathrm{O}_{1}, \mathrm{~W}_{2}$, and $\mathrm{O}_{3}$ also increases. Therefore, for a given downstream level, the upstream level $Z_{u}$ is increased when $k_{9}$ increases.

The upstream level $Z_{u}$ is mainly sensitive to $D$, which is fixed by the floats (Fig. 9). The most useful mode for the downstream regulation is Mode 4, and the curve for this mode can be easily adjusted by reducing the openings of $\mathrm{O}_{4}, \mathrm{O}_{3}$, and $\mathrm{O}_{9}$ with the shutters, as described previously. The sensitivity analysis is useful to adjust the shutters according to given target control levels.

- Because $Z_{4} \approx Z_{d}$ (downstream tank) and $Z_{3}=Z_{4}+D$ (upstream tank), the upstream tank level $\left(Z_{3}\right)$ is not significantly affected by any of the shutter settings.

- For a given $D, Z_{u}$ is mainly adjusted using shutters on $\mathrm{O}_{3}$ and $\mathrm{O}_{9}$.

However, shutter adjustment could increase the transitional time necessary to reach steady-state conditions. It may therefore disturb the normal functioning of the gate. For instance, if $Z_{4}$ decreases, the gate will open because the difference between $Z_{3}$ and $Z_{4}$ will be greater than $D$. If $Z_{3}$ is not rapidly adjusted by the flow through orifices (emptying of upstream tank) to get a head loss equal to $D$, the mixed gate will deliver a large discharge over a long time, compared to the situation without shutters. This transitional aspect is not taken into account in our steady-state model, but it imposes additional conditions for the adjustment of the orifice openings.

\section{Results and Discussion}

A mixed gate located on the Bas-Rhône Languedoc canal in southern France was equipped with a set of sensors to automatically record water levels and gate openings. The characteristics of this gate are provided in Table 2. Four sensors measured the water levels $Z_{1}, Z_{3}, Z_{4}$, and $Z_{6}$. Because $Z_{4}=Z_{d}$ and $Z_{1}$ is close to $Z_{u}$, the sensors were installed in the side tanks for convenience. A position sensor measured the distance from the float to the bed of the canal. This measurement was then converted to obtain the value of the opening angle, $\alpha$. The sampling rate was $3 \mathrm{~min}$ and the measurements were made continuously over a period of two months. 

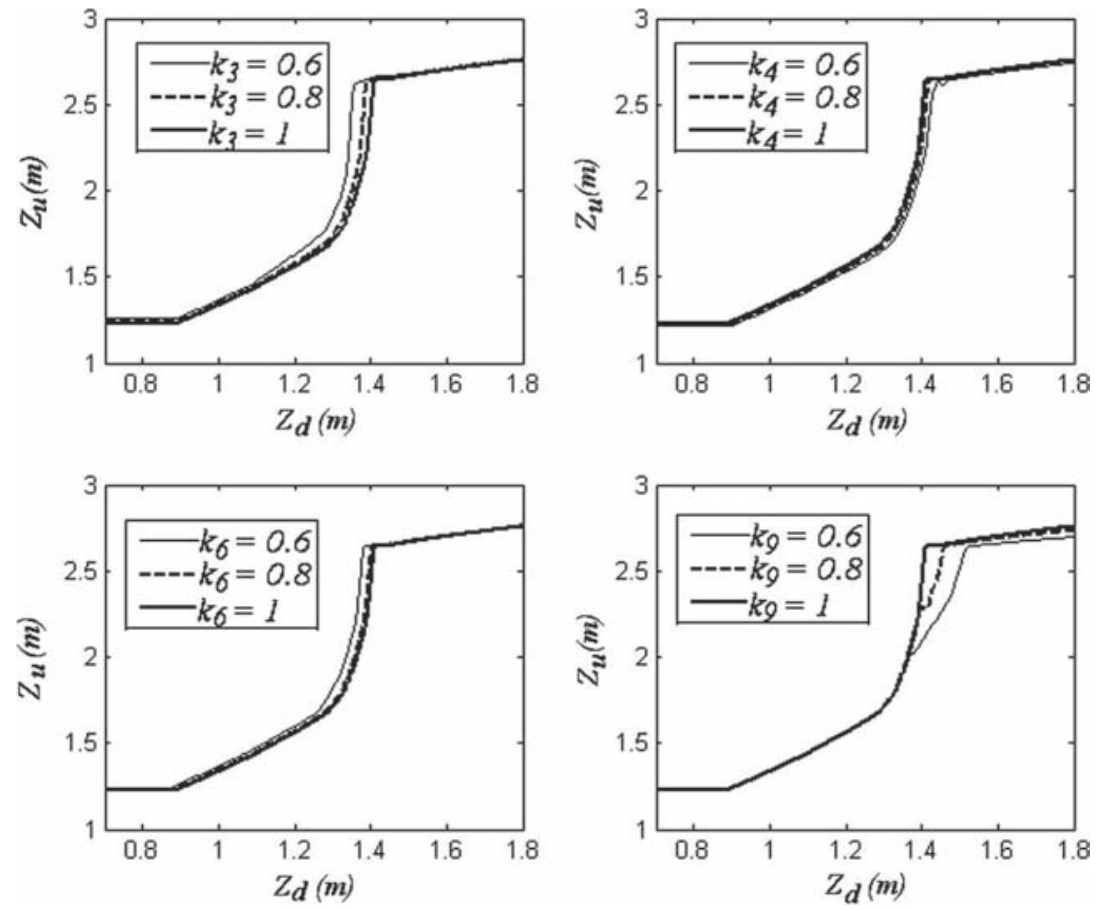

Fig. 8. Modeled curves of $Z_{u}$ as a function of $Z_{d}$ for various opening orifice coefficients $(D=0.3 \mathrm{~m}) ; k_{3}, k_{4}, k_{6}$, and $k_{9}$ are the relative opening coefficients of the orifice $O_{3}, O_{4}, O_{6}$, and $O_{9}$, respectively; discharge coefficients are given by Eq. (8) ( 0.6 for an orifice and 0.4 for a weir)

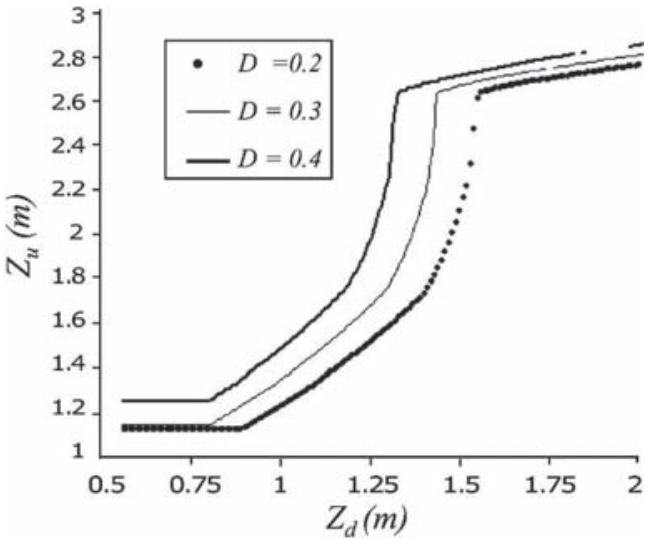

Fig. 9. Relationship between upstream level $Z_{u}$ and downstream level $Z_{d}$ for various values of parameter $D(\mathrm{~m})$. Discharge coefficients are given by Eq. (8) ( 0.6 for an orifice and 0.4 for a weir)

Table 2. Design Characteristics of the Experimental Gate

\begin{tabular}{lccccc}
\hline Number & Type & Crest level $(\mathrm{m})$ & $C_{d W}$ & $C_{d 0}$ & $L$ or diameter $(\mathrm{m})$ \\
\hline 1 & Orifice & 0.588 & 0.4 & 0.6 & 0.2 \\
2 & Weir & 0.996 & 0.4 & - & 0.8 \\
3 & Orifice & 0.588 & 0.4 & 0.6 & 0.1 \\
4 & Orifice & 0 & 0.4 & 0.6 & 0.05 \\
5 & Weir & 0.9 & 0.4 & - & 1.2 \\
6 & Orifice & 0.653 & 0.4 & 0.6 & 0.1 \\
7 & Orifice & 1.055 & 0.4 & 0.6 & Computed \\
8 & Orifice & 0.533 & 0.4 & 0.6 & 0.1 \\
9 & Orifice & 1.067 & 0.4 & 0.6 & 0.15 \\
10 & Weir & 2.208 & 0.4 & - & 1.2
\end{tabular}

During this period, three significant flow changes were observed, corresponding to a decrease in the flow, which caused a decrease of the upstream water level. The shutter adjustments were maintained constant, but they were not measured during the period. The test covered Modes 1-4. The noise because of the sensors or highfrequency fluctuations was filtered by a moving average method over $15 \mathrm{~min}$. Most of the time, the upstream and downstream water levels exhibited the same oscillations with two time periods. The first time period is about $3 \mathrm{~h}$ and is attributable to waves in the channel. The second period is about 1 day, corresponding to water withdrawals. When the water level decreased, the gate opened to maintain a constant discharge. The mixed gate was effective and regulated the water depths and flow in the channel at the gate location.

Flow changes were obtained by setting $Q_{p}$ to 0 , then $Z_{u}$ decreased and the gate opened to satisfy $Q_{d}$. This situation ended after few hours because the storage in the upstream reach was not sufficient. The mode of regulation changed and the downstream water level also decreased. The data corresponding to very small gate openings $\left(\alpha<1.5^{\circ}\right)$ were not considered in the analysis (see Fig. 5). For these data, the parameter $D$ increased linearly with $Z_{3}$ (it was not constant). This behavior cannot be explained by a defect of the counterweight mechanism, which must maintain a constant distance from the rotational axis. One possible explanation is that at small gate openings, friction on the gate bay may generate a small resistive torque. The model does not account for this effect, so these data have not been used in the analysis.

Given the number of adjustable parameters $\left(k\right.$ and $\left.C_{d}\right)$, optimization of these factors would have little meaning because the openings of the hydraulic structures inside the tanks cannot be verified and accurately measured. Moreover, not enough data are available to get the setting of each orifice. To fit the model to experiments, only the most sensitive orifice relative opening $k_{3}, k_{9}$, and the discharge coefficient $C_{d W 7}$ were calibrated by using the model defined by Eqs. (2)-(6). The calibration was made by minimizing the mean 


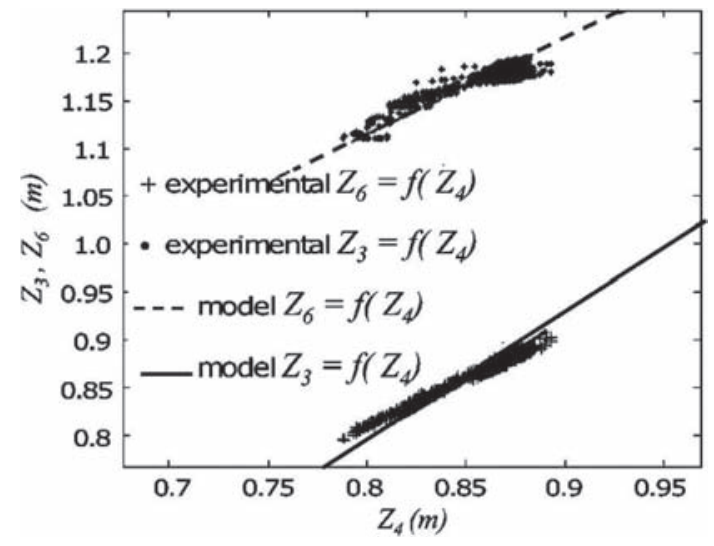

Fig. 10. Comparison of modeled curve (line) and measured data (sign) $\left(D=0.31 \mathrm{~m}, \quad C_{d O}=0.6, \quad C_{d W}=0.4, \quad C_{d W 7}=0.2, \quad k_{9}=0.78\right.$, $\left.k_{3}=0.88\right)$

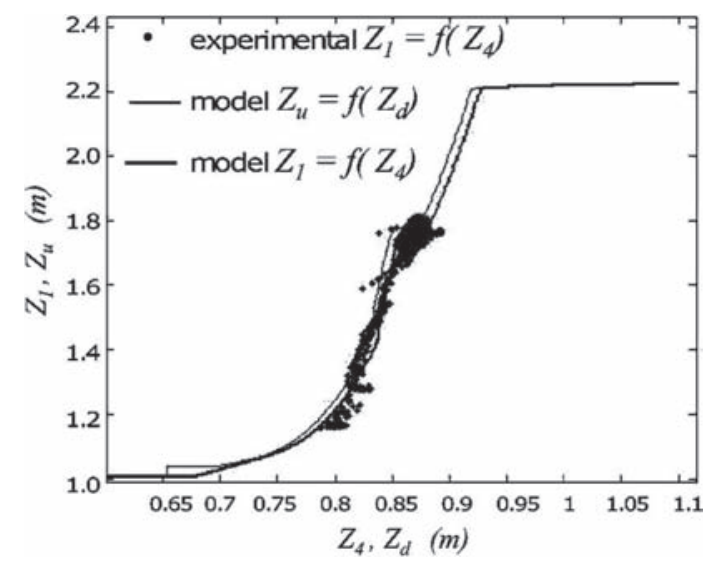

Fig. 11. Comparison of modeled curve (dash) and measured data (dot) $\quad\left(D=0.31 \mathrm{~m}, \quad C_{d O}=0.6, \quad C_{d W}=0.4, \quad C_{d W 7}=0.2, \quad k_{9}=\right.$ $\left.0.78, k_{3}=0.88\right)$; the modeled curve of $Z_{d}$ as a function of $Z_{u}$ is added

square error between experimental data $\left(Z_{1}, Z_{3}, Z_{4}\right.$, or $\left.Z_{6}\right)$ and simulated results.

- First, $D$ is fixed by the relationship between $Z_{3}$ and $Z_{4}$ [Fig. 10, Eq. (9)].

- Second, the flow balance $\left(Q_{7}=Q_{8}\right)$ in the midtank allows fitting the model to the experimental water level $\left(Z_{3}, Z_{4}\right.$ and $Z_{6}$ ) by adjusting $C_{d W 7}$ independently of other opening coefficients (Fig. 10).

- Third, the opening coefficients are adjusted to reproduce the design curve (Fig. 11). As shown in Fig. 8, $k_{3}$ and $k_{9}$ act in an opposite way on the curve and are limited to one, so only one solution is possible to fit curves for all modes $\left(k_{3}=0.88, k_{9}=0.78\right)$.

Fig. 11 shows that the model can satisfactorily reproduce the relationship between $Z_{1}$ and $Z_{4}$. On the same graph, the curve giving $Z_{u}$ as a function of $Z_{d}$ is depicted. As expected, both curves are similar because experimental observation showed that $Z_{u}$ and $Z_{d}$ are almost equal to $Z_{1}$ and $Z_{4}$, respectively. The range of gate operations is limited by the actual functioning of the irrigation network. Additional measurements are needed to validate our model outside this range.

Even if the experimental curve is similar to the design curve (Fig. 1), only Modes 4 and 5 are possible. For Modes 1, 2, and 3 , the difference between the weir height $W_{5}$ and $W_{2}$ is insufficient to permit flow in the tanks to ensure the opening of the gate. Furthermore, the difference of height between the bottom of the orifice $\mathrm{O}_{9}$ and the weir $\mathrm{W}_{5}$ is lower than $D$. Then flows through $\mathrm{O}_{9}$ and over $\mathrm{W}_{5}$ are possible. The security mode that avoids dewatering is provided by a mixed mode between Modes 1 and 4 .

\section{Conclusions}

A model was derived to describe the mixed gate, which is a particular hydromechanical gate that is able to combine an upstream control strategy in the upstream pool and a downstream control strategy in its downstream pool. A numerical algorithm has been proposed that establishes the relationships among the flow rate and the different water levels in the tanks and in the reaches. A univocal relation depending on flow and design characteristics was obtained. With this model, the influence of the different shutters installed on the orifices connecting the tanks was analyzed, and the analysis showed how they can be used to achieve the desired water levels. Comparisons between the model and experimental data have been made for an operating gate. A good agreement was observed between the model and the empirical data obtained on an operating mixed gate in the south of France.

The model derived here was implemented recently in SIC, the canal simulation software developed by Cemagref (Cemagref 2004) and used to analyze management strategies in modernizing irrigation schemes in Morocco.

\section{Acknowledgments}

The authors would like to acknowledge the support provided by the BRL Exploitation company for the field measurements.

\section{Notation}

The following symbols are used in this paper:

$C_{0}=$ torque due to floats $(\mathrm{N} \cdot \mathrm{m})$;

$C_{\text {counterweight }}=$ torque due to counterweight $(\mathrm{N} \cdot \mathrm{m})$;

$C_{d}=$ discharge coefficient of the hydraulic structures;

$C_{d O i}=$ discharge coefficient of hydraulic structure $i$ (functioning as an orifice);

$C_{d W i}=$ discharge coefficient of hydraulic structure $i$ (functioning as a weir);

$D=$ water level gap between upstream side tank and downstream side tank $(\mathrm{m})$;

$D_{O}=$ orifice diameter $(\mathrm{m})$;

$g=$ gravitational acceleration $\left(\mathrm{m} / \mathrm{s}^{2}\right)$;

$\mathrm{G}_{7}=$ name of grid between upstream and mid tanks;

$h_{1}=$ upstream device water head (m);

$h_{2}=$ downstream device water head (m);

$k_{i}=$ opening orifice coefficient of the orifice $\mathrm{O}_{i}$;

$L=$ equivalent width of device $(\mathrm{m})$;

$L_{7}=$ equivalent width of the grid $\mathrm{G}_{7}(\mathrm{~m})$;

$L_{f}=$ width of float (m);

$\mathrm{O}_{i}=$ name of orifice $i$;

$Q=$ discharge $\left(\mathrm{m}^{3} / \mathrm{s}\right)$;

$Q_{i}=$ discharge through or over the device $i\left(\mathrm{~m}^{3} / \mathrm{s}\right)$;

$Q_{d}=$ required discharge $\left(\mathrm{m}^{3} / \mathrm{s}\right)$;

$Q_{p}=$ provided discharge $\left(\mathrm{m}^{3} / \mathrm{s}\right) ;$

$r_{1}=$ outer radius of floats $(\mathrm{m})$;

$r_{2}=$ inner radius of floats $(\mathrm{m})$;

$w=$ orifice opening (m); 
$\mathrm{W}_{i}=$ name of weir $i$

$Z_{1}=$ water level in the inlet tank upstream of $\mathrm{W}_{2}(\mathrm{~m})$;

$Z_{2}=$ water level in the inlet tank downstream of $\mathrm{W}_{2}(\mathrm{~m})$;

$Z_{3}=$ water level in the upstream tank (m);

$Z_{4}=$ water level in the downstream tank upstream of $\mathrm{W}_{5}$ $(\mathrm{m})$;

$Z_{5}=$ water level in the downstream tank downstream of $\mathrm{W}_{5}(\mathrm{~m})$

$Z_{6}=$ water level in the mid tank $(\mathrm{m})$;

$Z_{7}=$ level of the grid bottom $(\mathrm{m})$;

$Z_{u}=$ water level in the upstream reach $(\mathrm{m})$;

$Z_{d}=$ water level in the downstream reach $(\mathrm{m})$;

$\alpha=$ opening angle of the gate leaf $\left(^{\circ}\right)$;

$\beta=$ parameter of the discharge coefficient law for orifice; and

$\rho=$ water density $\left(\mathrm{kg} / \mathrm{m}^{3}\right)$.

\section{References}

Alsthom. (1993). "Vanne mixte. Technical note." Rep. No. NT04130, France.

Belaud, G., Litrico, X., De Graaf, B., and Baume, J.-P. (2008). "Hydraulic modeling of an automatic upstream water-level control gate for submerged conditions." J. Irrig. Drain Eng., 134(3), 315-326.
Bos, M. (1989). Discharge measurement structures, 3rd Ed., International Institute for Land Reclamation and Improvement, Wageningen, Netherlands.

Brouwer, R. (1987). "Design and application of automatic check gate for tertiary turnouts." Proc., 13th Int. Congress on Irrigation and Drainage (ICID), Rabat, Morocco, 671-683.

Burt, C., Angold, R., Lehmkuhl, M., and Styles, S. (2001). "Flap gate design for automatic upstream canal water level control." J. Irrig. Drain Eng., 127(2), 84-91.

Cemagref. (2004). Simulation of irrigation canals (SIC) version 4.30: User's guide and theoretical concepts, France.

Chow, V. T. (1959). Open-channel hydraulics, McGraw-Hill, New York.

Litrico, X., Belaud, G., Baume, J.-P., and Ribot-Bruno, J. (2005). "Hydraulic modeling of an automatic upstream water-level control gate.” J. Irrig. Drain Eng., 131(2), 176-189.

Malaterre, P., Rogers, D., and Schurmans, J. (1998). "Classification of canal control algorithms." J. Irrig. Drain Eng., 124, 3-10.

Ramirez Luna, J. (1997). "Modélisation des ouvrages frontaux et latéraux dans les canaux d'irrigation." Ph.D. thesis, Engref (in French).

Sepulveda, C., Gomez, M., and Rodellar, J. (2009). "Benchmark of discharge calibration methods for submerged sluice gates." J. Irrig. Drain Eng., 135(5), 676-682.

Vlugter, H. (1940). "Over zelfwerkende peilregelaars bij den waterstaat in Nederlandsch-Indie.” De Ingenieur in Nederlandsch-Indie, 6, 84-93 (in Dutch). 